\title{
Efficacy of new intermittent abdominal pressure ventilator for post-ischemic cervical myelopathy ventilatory insufficiency
}

\author{
Paolo I. Banfi ${ }^{1}$, Eleonora Volpato ${ }^{1,2^{*}}$ (D) and John R. Bach ${ }^{3}$
}

\begin{abstract}
Non-invasive ventilation (NIV) is the treatment of choice for patients symptomatic for respiratory muscle dysfunction. It can normalize gas exchange and provide up to continuous non-invasive ventilator support (CNVS) as an alternative to intubation and tracheotomy. It is usually provided via non-invasive facial interfaces or mouthpieces, but these can be uncomfortable and uncosmetic. The intermittent abdominal pressure ventilator (IAPV) has been used for diurnal ventilatory support since 1938 but has been off the market since about 1990. Now, however, with greater emphasis on non-invasive management, a new IAPV is available. A patient with chronic ventilatory insufficiency post-ischemic cervical myelopathy, dependent on sleep NVS since 2003, developed symptomatic daytime hypercapnia for which he also used diurnal NVS via nasal pillows. However, he preferred not having to use facial interfaces. When not using diurnal NVS he was becoming dyspnoeic. Diurnal use of an IAPV was introduced. Arterial blood gas analysis using the IAPV decreased his blood pH from 7.45 to $7.42, \mathrm{PaCO}_{2}$ from 58 to $37 \mathrm{mmHg}$, and improved $\mathrm{PaO}_{2}$ from 62 to $92 \mathrm{mmHg}$. At discharge, the patient used the IAPV $8 \mathrm{~h} /$ day with improved mood and quality of life. Consequently, he returned to work as a painter.
\end{abstract}

Keywords: Non-invasive ventilation (NIV), Tracheostomy mechanical ventilation (TMV), Intermittent abdominal pressure ventilator (IAPV), Quality of life (QoL)

\section{Introduction}

Non-invasive ventilation or "NIV" has come to refer to continuous positive airway pressure (CPAP) or bi-level PAP used at setting inadequate for full non-invasive ventilator support (NVS). However, non-invasive positive pressure ventilation is increasingly being used for continuous NVS (CNVS) as an alternative to tracheostomy mechanical ventilation (TMV) for patients with ventilatory pump failure. Over 1000 CNVS users have been described [1-4]. It improves gas exchange, symptoms [5], quality of life [6], decreases the incidence of pneumonia [7], and can be used to avert need for intubation and

\footnotetext{
* Correspondence: eleonora.volpato@unicatt.it

${ }^{1}$ IRCCS Santa Maria Nascente, Fondazione Don Carlo Gnocchi, Milan, Italy

${ }^{2}$ Department of Psychology, Università Cattolica del Sacro Cuore, Milan, Italy

Full list of author information is available at the end of the article
}

tracheotomy [8]. Whereas tracheostomy tends to increase ventilator dependence, detracts from quality of life, and is associated with reactive depression, NIV/NVS facilitates ventilator weaning and extubation $[9,10]$. It is delivered via facial interfaces including nasal, oronasal, nasal prongs, and mouthpieces for diurnal and sleep ventilatory assistance/support [3]. However, the interfaces can cause skin discomfort and, at times, ulcerations, airway dryness and congestion and can impact negatively on quality of life and gas-exchange [11-13]. Moreover, oxyhemoglobin desaturations and dyspnea can occur with interface disconnection from NVS [11].

The LUNA DS (Dima Italia Inc., Bologna, Italy) is a portable ventilator, that along with the $\mathrm{PBAir}^{\mathrm{rm}}$ corset is an easy to use IAPV. The LUNA has an internal battery capacity that can also be used for NVS for sleep. It provides a dedicated IAPV ventilation mode. The IAPV corset is lightweight (Fig. 1), comfortable, and easy to don 

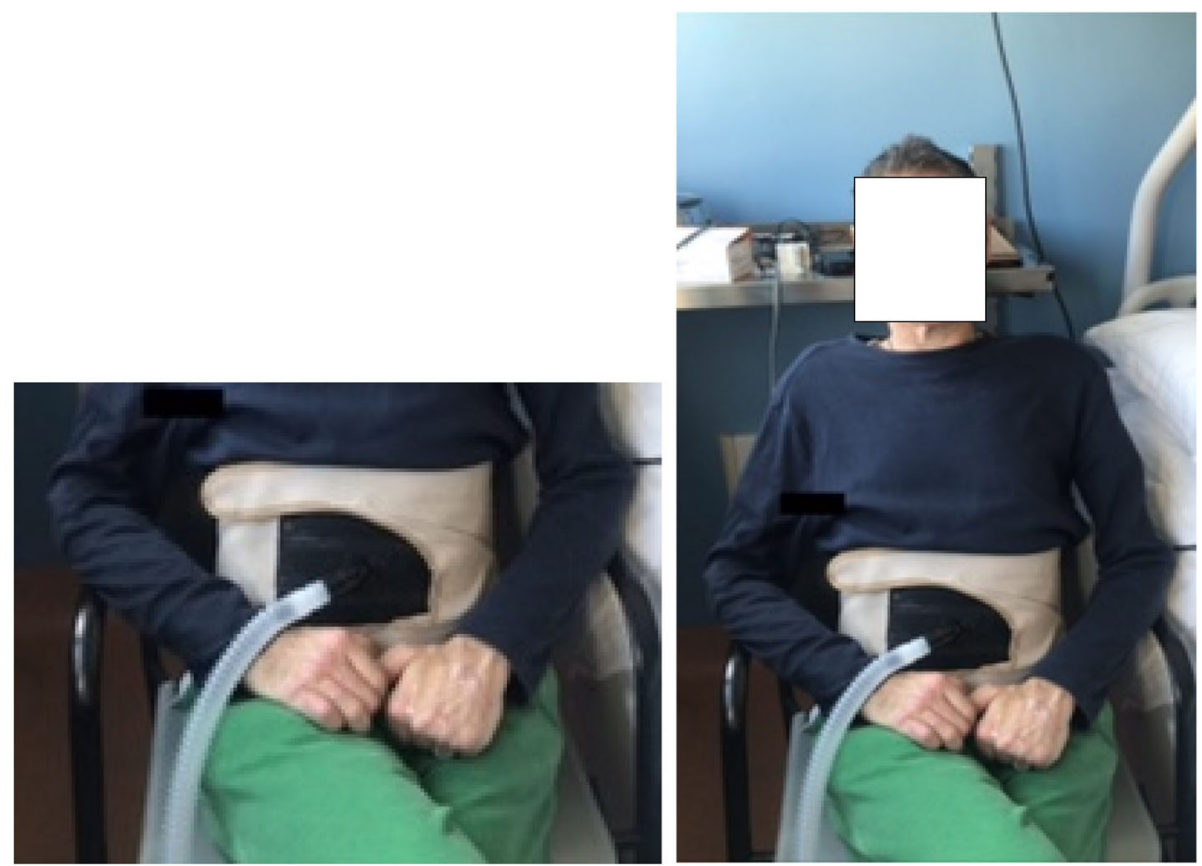

Fig. 1 The PBAir ${ }^{T M}$ corset and air bladder of the new IAPV

and fit with Velcro fasteners. Like earlier IAPVs, cyclical inflation of a rubber bladder inside the corset moves the diaphragm upwards to expel air from residual volume. This causes air to enter the lungs via the upper airway as gravity draws the diaphragm back to its resting position. The IAPV eliminates need for facial ventilation interfaces.

The following IAPV parameters can be set: PBelt ${ }^{\mathrm{tm}}$ (pressure inside the bladder), Tinsp (real inspiratory time when the diaphragm moves down), frequency (respiratory rate), and Rise Time (time to inflate the bladder). The IAPV only works efficiently when a patient is in sitting position at an angle of $30^{\circ}$ or greater and is optimal at $75^{\circ}$ [14]. It optimizes cosmesis, facilitates social interaction and communication, leaves the field of vision free, and allows the patient a more normal sense of smell by eliminating facial interfaces that are colonized by often pathogenic bacteria, thereby favouring oral nutrition $[15,16]$.

Table 1 Respiratory assessment: a comparison between spontaneous breathing and the intermittent abdominal pressure ventilator

\begin{tabular}{lllllll}
\hline & \multicolumn{2}{l}{ Spontaneous Breathing } & & IAPV/PBAir & \\
\cline { 2 - 3 } \cline { 6 - 7 } & Min & Max & & Min & Max \\
\hline Frequency & $25.4 \mathrm{cpm}$ & $35.3 \mathrm{cpm}$ & & $14.2 \mathrm{cpm}$ & $14.2 \mathrm{cpm}$ \\
Inspiratory Volume & $172 \mathrm{~mL}$ & $280 \mathrm{~mL}$ & & $771 \mathrm{~mL}$ & $908 \mathrm{~mL}$ \\
Expiratory Volume & $165 \mathrm{~mL}$ & $277 \mathrm{~mL}$ & & $791 \mathrm{~mL}$ & $923 \mathrm{~mL}$ \\
Flow & $-32.2 \mathrm{Llpm}$ & $+33.5 \mathrm{lpm}$ & & $-61.9 \mathrm{lpm}$ & $+56.1 \mathrm{lpm}$ \\
\hline
\end{tabular}

\section{Case report}

A 51-year-old male painter with a 40 pack/years history of cigarette smoking and a diagnosis of chronic respiratory failure due to post ischemic cervical myelopathy was trained in bi-level PAP which he used up to $16 \mathrm{~h}$ per day since 2003 at 25 inspiratory $\mathrm{cm}_{2} \mathrm{O}$ (IPAP) and 7 $\mathrm{cm} \mathrm{H}_{2} \mathrm{O}$ expiratory (EPAP) pressures and rate $15 / \mathrm{min}$. However, during the last year he experienced daytime dyspnoea, tachypnoea, orthopnea, and deterioration of gas exchange when not using it and complained of the interface causing discomfort and interfering with his daytime employment. His arterial blood gases (ABG) breathing unassisted in ambient air $4 \mathrm{~h}$ after discontinuing nocturnal bi-level PAP was $\mathrm{PaO}_{2} 62$ and $\mathrm{PaCO}_{2} 58$ mmHg. On admission, he was placed on IAPV ventilation. He wore the IAPV corset's horizontal upper border two fingers below the costophrenic junction.

His spontaneous tidal volumes of $172-180 \mathrm{ml}$ increased to 771-908 $\mathrm{ml}$ using the IAPV with the LUNA

Table 2 Pulmonary gas exchange

\begin{tabular}{lllll}
\hline & $\begin{array}{l}\text { Baseline } \\
\text { SB }\end{array}$ & $\begin{array}{l}\text { After 2 h during } \\
\text { IAPV }\end{array}$ & $\begin{array}{l}\text { 1 month } \\
\text { SB }\end{array}$ & $\begin{array}{l}3 \text { months } \\
\text { SB }\end{array}$ \\
\hline $\mathrm{Ph}$ & 7.45 & 7.42 & 7.45 & 7.42 \\
$\mathrm{PaO}_{2}$ & 62 & 92 & 71 & 75 \\
$\mathrm{PaCO}_{2}$ & 58 & 37 & 48 & 44 \\
$\mathrm{HCO}_{3}-1$ & $31.5 / 4.9$ & $28.2 / 1.9$ & $27.4 / 2.6$ & $25.2 / 0.9$ \\
$\mathrm{~EB}$ & & & \\
\hline $\begin{array}{l}\text { ABG Arterial Blood Gas Analysis, SB Spontaneous breathing, IAPV Intermittent } \\
\text { Abdominal Pressure Ventilation }\end{array}$
\end{tabular}


ventilator set at $24 \mathrm{~cm} \mathrm{H}_{2} \mathrm{O}$ pressure, rate $15 / \mathrm{min}$ (Table 1). Arterial blood gases were monitored after the second hour of IAPV use. Table 2 demonstrates normalization of the diurnal breathing pattern and gas exchange. After 3 months his $\mathrm{PaO}_{2}$ breathing unassisted in ambient air was 75 and $\mathrm{PaCO}_{2} 44 \mathrm{mmHg}$ (Table 2).

Quality of life parameters were measured and at discharge thanks to the EuroQoL (EQ-5D) [17] and the World Health Organization Quality of Life Questionnaire (WHOQOL-Bref) [18], the patient used the IAPV $8 \mathrm{~h} /$ day with improved mood (assessed by the Hospital Anxiety and Depression Scale (HADS) [19]) and cognition (as assessed by the Mini Mental Status Examination [20] and the Addenbrooke's Cognitive Examination Revised (ACE-R) [21] (Table 3). Moreover, three months later he reported that the IAPV was still effectively relieving his former daytime dyspnoea but that he had achieved up to $6 \mathrm{~h} / \mathrm{d}$ of autonomous breathing without dyspnoea or tachypnea.

\section{Discussion}

C. J. McSweeney described the Bragg-Paul Pulsator, a IAPV that was used for 34 patients with acute diphtheritic respiratory muscle paralysis in 1938 [22-24]. The IAPV was perfected by Dr. Alvin Barach and his engineer William Smith in the 1940s [23]. Until the 1990s it was used in combination with NVS modalities instead of tracheostomy mechanical ventilation (TMV). However, with the treatment paradigm shift to TMV in the 1960s, the IAPV went off the market and there have been no major publications of patients using it since 1991 [22]. Now, however, with the paradigm shifting back to non-invasive management and over the last decade over 1500750 CNVS users described [1-4], the IAPV is back on the European market $[12,13,25,26]$ and consideration of this practical, convenient, and comfortable daytime ventilation alternative is warranted. IAPV use had been limited by the relative lack of portability and inconvenience of formerly available large and heavy powerful ventilators needed to operate them, and the fact that clothing could catch on the corset buckles. Use of the IAPV had also never been reported by patients with cervical myelopathies. In our patient, the IAPV improved blood gases, relieved dyspnoea, and continued to be a comfortable alternative to bi-level PAP.

\section{Conclusion}

This case of IAPV use for ventilatory assistance for a patient with a post-ischemic cervical myelopathy suggests that it can be a safe and comfortable alternative to daytime NIV and TMV leading to a better quality of life for this patient population.

Table 3 Principal data of the psychological evaluation pre- and post- use of the IAPV

\begin{tabular}{|c|c|c|c|c|c|c|}
\hline \multicolumn{7}{|l|}{ Psychological Evaluation } \\
\hline Age, years: & 51 & & & & & \\
\hline Profession: & Artist & & & & & \\
\hline Manual predominance: & Dx & & & & & \\
\hline \multirow[t]{2}{*}{ Test } & Admission & & & Discharge & & \\
\hline & Raw Score & Adjusted Score & Equivalent Score & Raw Score & Adjusted Score & Equivalent Score \\
\hline Spatial orientation [20]: & $5 / 5$ & & & $5 / 5$ & & \\
\hline Time orientation [20]: & $5 / 5$ & & & $5 / 5$ & & \\
\hline Mini Mental State Examination (MMSE) [20]: & 27 & & Non Case & 29 & & Non Case \\
\hline Addenbroke's Examination (ACE-R) [21]: & $86 / 100$ & 84.89 & 3 & $88 / 100$ & 86.89 & 3 \\
\hline EuroQoL (EQ-5D) [17]: & 31211 & & & 21111 & & \\
\hline Index EQ-5D [17]: & 0.3 & & & 0.85 & & \\
\hline Visual Analogue Scale (VAS EQ-5D) [17]: & 60 & & & 100 & & \\
\hline $\begin{array}{l}\text { World Health Organization Quality of Life } \\
\text { Questionnaire-Bref (WHOQoL-Bref) [18]: }\end{array}$ & 92 & & & 109 & & \\
\hline Physical Domain: & 10.66 & 41.66 & & 19.33 & 95.83 & \\
\hline Psychological Domain: & 20 & 100 & & 21.6 & 110 & \\
\hline Environment Domain: & 20 & 100 & & 20.66 & 104.16 & \\
\hline Social Domain: & 26 & 137.5 & & 28 & 150 & \\
\hline Hospital Anxiety and Depression Scale (HADS) [19]: & $25 / 42$ & & & $5 / 42$ & & \\
\hline HAD-A: & $11 / 21$ & & Moderate & $4 / 21$ & & Non Case \\
\hline HAD-D: & $7 / 21$ & & Non Case & $1 / 21$ & & Non Case \\
\hline
\end{tabular}




\section{Abbreviations}

ABG: Arterial Blood Gases; CNVS: Continuous Non-Invasive Ventilatory Support; CPAP: Continuous Positive Airway Pressure; EPAP: Expiratory Positive Air Pressure; IAPV: Intermittent Abdominal Pressure Ventilator; IPAP: Inspiratory Positive Air Pressure; NIV: Non-invasive Ventilation; NVS: Non-Invasive Ventilator Support; TMV: Tracheostomy Mechanical Ventilation

\section{Acknowledgements}

We would like to thank Dima Italia S.r.l. for providing the LUNA DS device and to have performed PbAir corset.

\section{Confidentiality of data}

The authors declare that they have followed the protocols of their work centre on the publication of patient data.

\section{Right to privacy and informed consent}

The authors have obtained the written informed consent of the patient mentioned in the article. The corresponding author is in possession of this document.

\section{Authors' contributions}

BP contributed to the study design, VE contributed to the literature search, implementation and data collection of the case report as well as to the psychological assessments. JRB supervised and revised the manuscript, including the English language. All authors read and approved the final manuscript.

\section{Ethics approval and consent to participate}

The study protocol was submitted to the Ethics Committee of the Section "IRCCS Fondazione Don Carlo Gnocchi" IRCCS Regione Lombardia. Protection of human and animal subjects. The authors declare that the procedures followed were in accordance with the regulations of the relevant clinical research ethics committee and with those of the Code of Ethics of the World Medical Association (Declaration of Helsinki). The authors have obtained the written informed consent of the patient mentioned in the article

\section{Competing interests}

The authors declare that they have no competing interests.

\section{Publisher's Note}

Springer Nature remains neutral with regard to jurisdictional claims in published maps and institutional affiliations.

\section{Author details}

'IRCCS Santa Maria Nascente, Fondazione Don Carlo Gnocchi, Milan, Italy. ${ }^{2}$ Department of Psychology, Università Cattolica del Sacro Cuore, Milan, Italy. ${ }^{3}$ Department of Physical Medicine and Rehabilitation, Rutgers University New Jersey Medical School, Newark, USA.

Received: 2 August 2018 Accepted: 20 November 2018

Published online: 28 January 2019

\section{References}

1. Bach JR Gonçalves MR, Hamdani I, Winck JC. Extubation of Patients With Neuromuscular Weakness: A New Management Paradigm, Chest 2010;137; 1033-39; Prepublished online December 29, 2009. https://doi.org/10.1378/ chest.09-2144.

2. Bach JR. Noninvasive respiratory Management of Patients with Neuromuscular Disease. Ann Rehabil Med. 2017;41 (4):519-38.

3. Hess DR. Noninvasive ventilation for neuromuscular disease. Clin Chest Med. 2018;39(2):437-47

4. Bach JR, Alba AS, Saporito LR. Intermittent positive pressure ventilation via the mouth as an alternative to tracheostomy for 257 ventilator users. Chest. 1993;103(1):174-82.

5. Bach JR, Alba AS. Management of chronic alveolar hypoventilation by nasal ventilation. Chest. 1990;97(1):52-7.

6. Butz M, Wollinsky KH, Wiedemuth-Catrinescu U, Sperfeld A, Winter S, Mehrkens $\mathrm{HH}$, et al. Longitudinal effects of noninvasive positive-pressure ventilation in patients with amyotrophic lateral sclerosis. Am J Phys Med Rehabil. 2003;82(8):597-604.
7. Bach JR, Martinez D. Duchenne muscular dystrophy: prolongation of survival by noninvasive interventions. Respir Care. 2011;56(6):744-50.

8. Pinto T, Chatwin M, Banfi P, Winck JC, Nicolini A. Mouthpiece ventilation and complementary techniques in patients with neuromuscular disease: a brief clinical review and update. Chron Respir Dis. 2017;14(2):187-93.

9. Bach JR, Goncalves MR, Rodriguez PL, Saporito L, Soares L. Cuff deflation: rehabilitation in critical care. Am J Phys Med Rehabil. 2014;93:719-23.

10. Sancho J, Servera E, Díaz JL, Banuls P, Marín J. Home tracheotomy mechanical ventilation in patients with amyotrophic lateral sclerosis: causes, complications and 1-year survival. Thorax. 2011;66:948-52.

11. Bach JR. Response to Vianello et al. letter to the editor on: Bach JR, Gonçalves MR, Hamdani I, Winck JC. Extubation of unweanable patients with neuromuscular weakness: a new management paradigm. Chest. 2010; 138(1026-27).

12. Miller HJ, Thomas E, Wilmot CB. Pneumobelt use among high quadriplegic population. Phys Med Rehabil. 1988;69:369-72

13. Yang GW, Alba A, Lee M, Khan A. Pneumobelt for sleep in the ventilator user: clinical experience. Arch Phys Med Rehabil. 1989;70:707-11.

14. Hill SN. Clinical applications of body ventilators. Chest. December 1986;90(6): 897-905.

15. Bach JR. A comparison of long-term ventilatory support alternatives from the perspective of the patient and caregiver. Chest. 1993:104:1702-6.

16. Bach JR. Noninvasive mechanical ventilation. Philadelphia: Hanley and Belfus; 2002

17. Balestroni G, Bertolotti G. L'EuroQol-5D (EQ-5D): uno strumento per la misura della qualità della vita. Monaldi Arch Chest Dis-Cardiac Series. 2012; 78(3);155-9.

18. Skevington SM, Lotfy M, O'Connell KA. The World Health Organization's WHOQOL-BREF quality of life assessment: psychometric properties and results of the international field trial. A report from the WHOQOL group. Send to Qual Life Res. 2004;13(2):299-310.

19. Zigmond AS, Snaith RP. The hospital anxiety and depression scale. Acta Psychiatr Scand. 1983:67:361-70.

20. Magni E, Binetti G, Bianchetti A, Rozzini R, Trabucchi M. Mini-mental state examination: a normative study in Italian elderly population. Eur J Neurol. 1996;3:198-202

21. Pigliautile M, Chiesi F, Rossetti S, Conestabile Della Staffa M, Ricci M, Federic $\mathrm{S}$, et al. Normative data for the ACE-R in an Italian population sample. Neurol Sci. 2015:36(12):2185-90.

22. Bach JR, Markstrom A. Noninvasive ventilation is more than mask ventilation. Chest. 2003;123(6):2156.

23. Bach JR. A historical perspective on the use of noninvasive ventilatory support alternatives. Respir Care Clin N Am. 1996;2(2):161-81.

24. McSweeney CJ. The Bragg-Paul Pulsator in treatment of respiratory paralysis Br Moo J. 1938;1:1206-7

25. Bach JR, Alba AS. Intermittent abdominal pressure ventilator in a regimen of noninvasive ventilatory support. Chest. 1991;99(3):630-6.

26. Bach JR, Morrison RS. Continuous noninvasive ventilatory support for patients with respiratory muscle dysfunction. UpToDate Topic. 2017;5116.

\section{Ready to submit your research? Choose BMC and benefit from:}

- fast, convenient online submission

- thorough peer review by experienced researchers in your field

- rapid publication on acceptance

- support for research data, including large and complex data types

- gold Open Access which fosters wider collaboration and increased citations

- maximum visibility for your research: over $100 \mathrm{M}$ website views per year

At BMC, research is always in progress.

Learn more biomedcentral.com/submissions 